\title{
Gravity pattern in southeast margin of Tibetan Plateau and its implications to tectonics and large earthquakes
}

\author{
Yue $\mathbf{W u}^{*}$, and Yuan Gao \\ Key Laboratory of Earthquake Prediction, Institute of Earthquake Forecasting, China Earthquake Administration, Beijing 100036, China
}

\begin{abstract}
There are many active faults in the southeast margin of Tibetan Plateau, where three large active faults zones, the Longmenshan, Xianshuihe and Anninghe, merge to form a "Y" shape. Strong crustal deformation and a complicated fault distribution accompany strong earthquake activity in this zone. In this paper, we investigate a multi-scale gravity anomaly in the southeastern margin of the Tibetan Plateau using the wavelet transform; we find that the pattern of the gravity field is closely related to the fault system in the study area. Analyzing the characteristics of this Bouguer gravity anomaly at different orders indicates that the eastern Himalayan syntaxis has produced a strong eastward push during its northward movement, resulting in a shortening of the crust from west to east and a rapid uplift of the Tibetan Plateau. The Songpan-Garzê and Sichuan-Yunnan blocks have been forced to slip and extrude southward and eastward laterally. The distributions of seven large earthquakes from 1970 to 2018 reflects the relationship between large earthquakes and characteristics of the gravity anomaly. Comparing the tectonic backgrounds of several earthquakes reveals that the large earthquakes occur usually in the high gravity anomaly gradient zone, which corresponds in general to the boundary zones of the blocks. We infer that large earthquakes occur primarily in high Bouguer gravity anomaly zones in the upper crust, while low Bouguer gravity anomalies encompass the lower crust and the uppermost mantle.
\end{abstract}

Keywords: southeast margin of Tibetan Plateau; Bouguer gravity anomaly (BA); wavelet transform (WT) and multiscale analysis (MA); focal mechanism of earthquake; gradient zone

Citation: Wu, Y., and Gao, Y. (2019). Gravity pattern in southeast margin of Tibetan Plateau and its implications to tectonics and large earthquakes. Earth Planet. Phys., 3(5), 425-434. http://doi.org/10.26464/epp2019044

\section{Introduction}

The collision between the Indian and Eurasian plates, began 45 Ma ago, and caused a strong uplift and thickening in the eastern margin zone of the Tibetan Plateau (Molnar and Tapponnier, 1975; England and Houseman, 1986; Teng JW et al., 1997). In different geological periods, the tectonic evolution of this area has obviously been restricted and influenced by three tectonic domains-the Tethys-Himalaya, the littoral Pacific, and the PaleoAsia (Royden et al., 1997; Clark and Royden, 2000). The Chinese mainland is divided into an eastern part and a western part by the north-south tectonic belt, which controls the eastward expansion of the Tibetan Plateau. The Southeast (SE) margin zone of the Tibetan Plateau is located geographically in the central and southern sections of the north-south tectonic belt (Figure 1). The northeastward thrusting Indian Plate under the Eurasian Plate resulted in a northeastward compression and an eastward extrusion (Tapponnier et al., 1982). The Tibetan Plateau, blocked by the hard craton of the Sichuan Basin, has partially migrated in the SE direction into the southern part of the Sichuan-Yunnan region. The characteristics of the regional crustal movements in the Sichuan-Yunnan region are attributable primarily to the wedging

Correspondence to: Y. Wu, amayandy1716@sina.com

Received 01 MAR 2019; Accepted 05 JUL 2019.

Accepted article online 05 AUG 2019.

C 2019 by Earth and Planetary Physics. of the eastern Himalayan syntaxis and the weak obstruction of the South China block (SCB). The diversity of crustal movements is manifested primarily in the activities of the large faults, which have formed a regular distribution of active faults in the SE margin zone of the Tibetan Plateau. The Longmenshan, Anninghe and Xianshuihe faults zones form important boundaries of the SCB, the Sichuan-Yunnan Block (SYB), and the Songpan-Garzê Block $(\mathrm{SGB})$. The fragmented regional structures and the frequent strong earthquakes in this area are induced primarily by the mutually collective impacts (Zhang PZ et al., 2003).

Over the past few decades, researchers have analyzed the characteristics of the gravity field and investigated the continuous uplift of the Eastern Tibetan Plateau. The relationships among the crustal structure, isostatic anomalies, and earthquakes have also been discussed in light of historical earthquake data (Jiang FZ and Fang J, 2001; Jiang XD and Jin Y, 2005; Lou H and Wang CY, 2005; Li Y et al., 2005; Zhang YQ et al., 2009). Even though the elevation difference between the Longmenshan fault zone and the Sichuan Basin is very obvious, this is not the relationship between the foreland basin and the thrust fold belt. The Cenozoic crustal shortening between the Longmenshan fault zone and the Sichuan Basin is very small; the same is true for the entire eastern margin of the Tibetan Plateau (Burchfiel et al., 2008). Royden et al. (1997) proposed a geodynamic model of lower crustal channel flow, considering a viscous flow layer with a thickness of $15 \mathrm{~km}$ in the middle and lower crust of the eastern margin of the Tibetan Plateau, flow- 


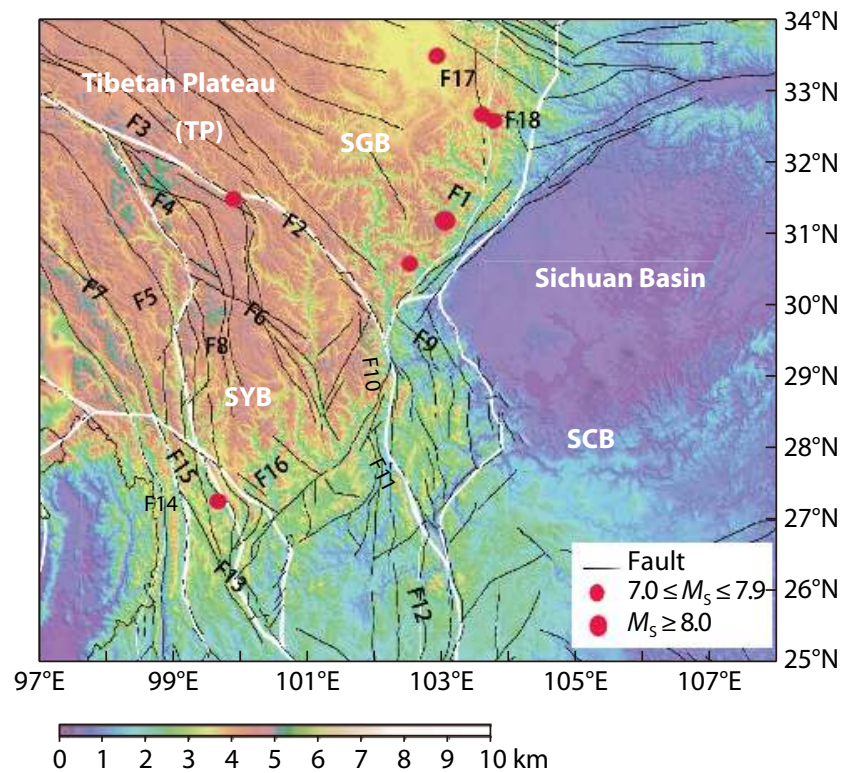

Figure 1. Tectonic background in the SE margin zone of the Tibetan Plateau. The white lines represent the boundaries of the blocks. The black lines represent the faults. SGB, Songpan-Garzê Block; SYB, Sichuan-Yunnan Block; SCB, South China Block; F1, Longmenshan fault; F2, Xianshuihe fault; F3, Garzê-Yushu fault; F4, Baiyu fault; F5, Batang fault; F6, Litang fault; F7, Lancangjiang fault; F8, Jinshajiang fault; F9, Daliangshan fault; F10, Anninghe fault; F11, Zemuhe fault; F12, Xiaojiang fault; F13, Lancangjiang fault; F14, Honghe fault; F15, Deqên-Zhongdian fault; F16, Lijiang-Xiaojin fault; F17, Minjiang fault; F18, Huya fault. Red solid circles indicate the earthquakes with $M_{\mathrm{S}} \geq$ 7.0.

ing outward to the plateau. After being blocked by the strong rigidity of the crust of the Sichuan Basin, the middle and lower crust accumulated, resulting in crustal thickening. South of the $\mathrm{Xi}$ anshuihe fault, the crust is relatively weak and the channel flow of the middle and lower crust opens up so that the crust thickens gradually in range to thousands of kilometers. This results in a large-scale uplift of the surface, forming a broad geomorphological contrast. The SE margin of the Tibetan Plateau is obviously blurred.

Investigations of the gravity-derived and isostatic crustal thicknesses suggest that the Longmenshan fault zone is not in an isostatic state (Wang QS et al., 2008). The Longmenshan fault zone is a part of the high gravity gradient zone around the Tibetan Plateau. Its density boundary extends downward in the NW direction and cuts through the Moho (Wang QS et al., 2009). The distribution of earthquake activities in this area is not only controlled by the fault structures but is also related to deep density changes (Zhang YQ et al., 2010). The unusually high Poisson ratio (>0.33) at the junction of the three fault zones (Wang CY et al., 2010) suggests an enrichment of iron and magnesium components and a local melting of the lower crust (Zandt and Ammon, 1995; Wang CY et al., 2010).

These previous studies have greatly advanced our understanding of the geophysical fields in the study area. The Longmenshan, $\mathrm{Xi}$ anshuihe and Anninghe fault zones greatly influence the crustal motion and play a regulating and restricting role with respect to the movement of the entire Eastern Tibetan Plateau. The strong earthquakes in the SE margin zone of the Tibetan Plateau occur primarily on the boundaries of active blocks (Jin HL et al., 2019). Earthquake activities are closely related to active faults. The seismicity in the continental lithosphere is the result of tectonic motion. The neotectonic movements are intense in this area. Earthquake activities in the SE margin zone of the Tibetan Plateau is of high frequency and high intensity.

The wavelet transform (WT) is a powerful tool for the decomposition of regional gravity anomalies and has been used effectively to investigate crustal structures (Hou ZZ and Yang WC, 1997; Yang WC et al., 2016; Ma ZW et al., 2017; Ren FL et al., 2018). In this paper, we use gravity data and WTs to analyze the crustal density structure in the study area and to detect deep characteristics of boundary faults between neighboring blocks. In view of the seismicity, the relationship between strong earthquake activity and regional active faults needs to be investigated further, as well as the current movement state of active blocks and the deep tectonic environment.

\section{Tectonic Setting}

The Sichuan-Yunnan region is located in the SE margin zone of the Tibetan Plateau, which lies in the central and southern sections of the north-south seismic belt. The typical features of the tectonic geomorphology in the SE margin zone of the Tibetan Plateau include an abrupt change in the topography along the Longmenshan fault zone, striking northeast in the northern part of the study area, and relatively slow change in the southern part of the study area (Figure 1).

Tectonically, the Xianshuihe, Jinshajiang, Anninghe, and Longmenshan fault zones constitute the locally important geological and geophysical boundaries of the SCB, SGB, and SYB (Figure 1). In view of the tectonic evolution of the region, this zone has undergone complex tectonic landform processes and tectonic transformations (Zhang YQ et al., 2009, 2010). During the late Miocene and Pliocene, the eastward extrusion of the Tibetan Plateau block resulted in a multi-episode orogenesis caused by compression and a strong thrust of the base along the Minshan and Longmenshan fault zones in the east margin zone (Xiong $X$ et al., 2005). The Minshan uplift zone and the Longmenshan tectonic zone rose rapidly during this period, and the orogenesis was probably completed in the late part of the early Pleistocene (approximately 780 ka) (Xu XW et al., 2005; Zhang ZJ et al., 2004). During the middle Pleistocene (approximately 780-130 ka), the east margin of the Tibetan Plateau was in a relatively stable and weak extensional state, and a series of valley landforms controlled by faults were formed along this geomorphologic boundary (Thatcher, 2007). From the late Pleistocene to the Holocene (from 126 ka to the present), the eastern margin of the Tibetan Plateau again entered a stage of compressional thrust-strike-slip deformation (Long SS and Zhao Z, 2000). The present tectonic activity and earthquakes are a continuation and manifestation of this latest active tectonic stage (Zhang YQ et al., 2010).

Crustal structures can reflect the process of crustal movements and evolution (Jiang FZ and Fang J, 2001) and are important in 
studies of crustal dynamics and earthquake preparation processes. Bouguer gravity anomaly (BA) data consist of a superposition of the crustal layers structures and extension effects and can reflect differences in the density of the crust. Using the FA2BOUG program (Fullea et al., 2008) with the latest 1 ' $\times 1$ ' interval global terrain data model topo_15.1.img (Smith and Sandwell, 1994) and free air gravity anomaly data obtained from EGM2008 (Zhang CY et al., 2009; Yang JY et al., 2012; Fu GY et al., 2013), the BA at 2' $\times 2$ ' interval in the SE margin of the Tibetan Plateau was calculated, as shown in Figure 2. Figure 2 primarily reflects the features of deep structures. This zone is located on the third step of the regional gravity field in the Chinese mainland (Lou H and Wang CY, 2005), a gravity gradient zone whose overall performance gradually decreases from southeast to northwest, indicating the tendency of the crustal thickness. The gravity field characteristics show differences between fault zones around the blocks and other fault zones within the blocks, indicating differences in the deep structure. These faults cause isoline distortions or gradient zone distributions of the gravity anomaly, which always correlate with surface deformation and gravity field change (Chen S et al., 2013). There are two distinct gradients of variation in the BA. One strikes $\mathrm{NNE}$, roughly consistent with the Longmenshan fault zone (thrust dominated); the other is around the Lijiang-Xiaojinhe fault (sinistral strike-slip with thrust) (Wang $Q$ et al., 2001). This pattern of density distribution is favorable for the lateral extrusion of the Sichuan-Yunnan rhombic block along the fault zone. The gradient zone of the BA is very clear, with a strike in the northern part is sub-parallel to the Longmenshan fault zone, while in the southern part, it is sub-parallel to the Anninghe fault and Zemuhe fault, that is, to the eastern boundary of the Sichuan-Yunnan rhombic block. In addition, within the rhombic block, the BA gradient zone is roughly sub-parallel to the Lijiang-Xiaojinhe fault, which appears to divide the rhombic block into two portions, a northern section and a southern section. These gradient zones are closely related to the faults.

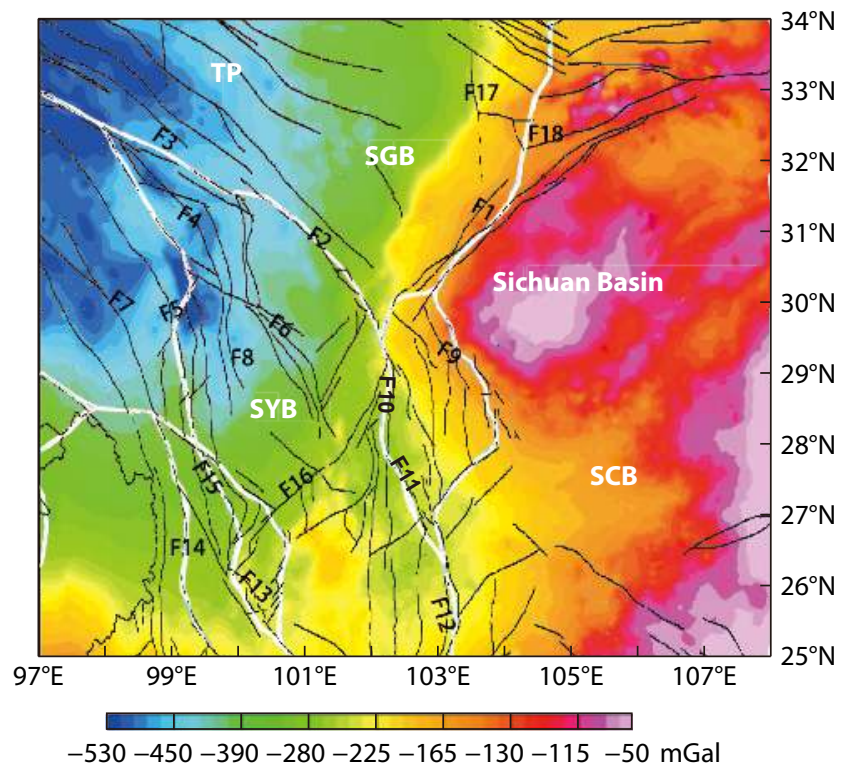

Figure 2. Bouguer gravity anomaly in study area. The abbreviations of tectonic blocks and faults are defined in the caption of Figure 1.

\section{Methods: Multiscale Analysis (MA) of the Gravity}

Anomalies

Mallat (1989) first proposed the theory of wavelet transform (WT) and multiscale analysis (MA). Superposed on the regional field, the gravity fields reveal the effects of the crustal structure at different depths. The WT method has been used widely in the field of geophysical signal processing. Because MA can decompose space into a series of subspaces with different resolutions and can decompose the original function into projections in different subspaces, it is a useful tool for studying the multiscale decomposition of gravity anomalies.

Since the introduction of MA, understanding of gravity fields has improved significantly (Mallat and Wang WL, 1992). A large number of calculation results demonstrate its superiority in gravity data processing applications. Using WT and MA, the BA in the Chinese mainland was analyzed to retrieve additional important information (Hou ZZ and Yang WC, 1997). The WT provided a new way to separate and process gravity anomalies (Yang WC et al., 2001).

At present, the algorithm most used in MA is the tower algorithm (Mallat, 1989; Hou ZZ and Yang WC, 2011).

Let $\left\{V_{j}\right\}_{j \in Z}$ be a one-dimensional MA. The scaling function is $\phi$, and the wavelet function is $\varphi$. If $V_{j}^{2}=V_{j} \otimes V_{j}$, then $\left\{V_{j}^{2}\right\}_{j \in Z}$ constitutes a two-dimensional MA. The two-dimensional scaling function is

$$
\Phi(x, y)=\phi(x) \phi(y) \text {. }
$$

The two-dimensional wavelet functions are

$$
\begin{aligned}
\psi^{1}(x, y) & =\phi(x) \varphi(y), \\
\psi^{2}(x, y) & =\varphi(x) \phi(y), \\
\psi^{3}(x, y) & =\varphi(x) \varphi(y) .
\end{aligned}
$$

Let function $f(x, y) \in V_{j_{1}}^{2}$. According to WT and MA principles, the following is true:

$$
\begin{gathered}
f(x, y)=A_{J_{1}} f(x, y)=A_{J_{1}+1} f(x, y)+\sum_{\varepsilon=1}^{3} D_{J_{1}+1}^{\varepsilon} f(x, y), \\
A_{J_{1}+1} f(x, y)=\sum_{m_{1}, m_{2} \in Z} C_{J_{1}+1, m_{1}, m_{2}} \Phi_{J_{1}+1, m_{1}, m_{2}}, \\
D_{J_{1}+1}^{\varepsilon} f(x, y)=\sum_{m_{1}, m_{2} \in Z} d_{J_{1}+1, m_{1}, m_{2}}^{\varepsilon} \psi_{J_{1}+1, m_{1}, m_{2}}^{\varepsilon},
\end{gathered}
$$

where

$$
\begin{aligned}
& C_{J_{1}+1, m_{1}, m_{2}}=\sum_{k_{1}, k_{2} \in Z} h_{k_{1}-2 m_{1}} h_{k_{2}-2 m_{2}} C_{J_{1}, k_{1}, k_{2}}, \\
& d_{J_{1}+1, m_{1}, m_{2}}^{1}=\sum_{k_{1}, k_{2} \in Z} h_{k_{1}-2 m_{1}} g_{k_{2}-2 m_{2}} C_{J_{1}, k_{1}, k_{2}}, \\
& d_{J_{1}+1, m_{1}, m_{2}}^{2}=\sum_{k_{1}, k_{2} \in Z} g_{k_{1}-2 m_{1}} h_{k_{2}-2 m_{2}} C_{J_{1}, k_{1}, k_{2}}, \\
& d_{J_{1}+1, m_{1}, m_{2}}^{3}=\sum_{k_{1}, k_{2} \in Z} g_{k_{1}-2 m_{1}} g_{k_{2}-2 m_{2}} C_{J_{1}, k_{1}, k_{2}} .
\end{aligned}
$$

Equation (5) can also be decomposed to step $J_{2}-J_{1}$, that is 


$$
\begin{array}{r}
f(x, y)=A_{\jmath_{2}} f(x, y)+\sum_{j=J_{1}+1}^{J_{2}} \sum_{\varepsilon=1}^{3} D_{j}^{\varepsilon} f(x, y), \\
A_{j} f(x, y)=\sum_{m_{1}, m_{2} \in Z} C_{j, m_{1}, m_{2}} \Phi_{j, m_{1}, m_{2},} \\
D_{j}^{\varepsilon} f(x, y)=\sum_{m_{1}, m_{2} \in Z} d_{j, m_{1}, m_{2}}^{\varepsilon} \psi_{j, m_{1}, m_{2}}^{\varepsilon}, \\
\\
\text { Where } j=J_{1}+1, \ldots, J_{2} .
\end{array}
$$

Let the two-dimensional gravity anomaly: be denoted as $\Delta g(x, y)=f(x, y)$. The expression of the gravitational decomposition can then be summarized as

(a)

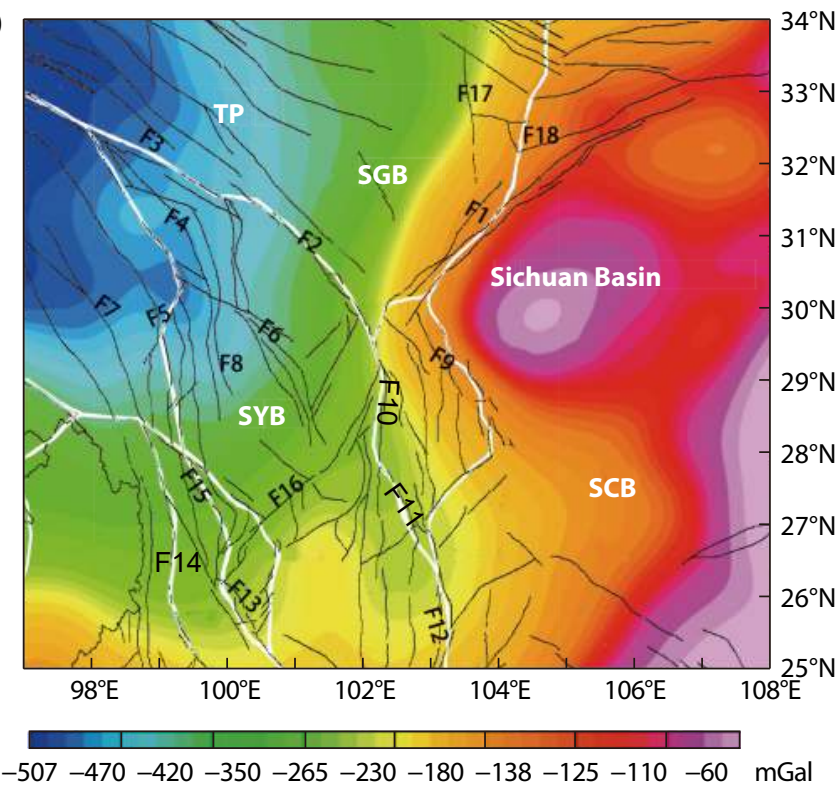

(c)

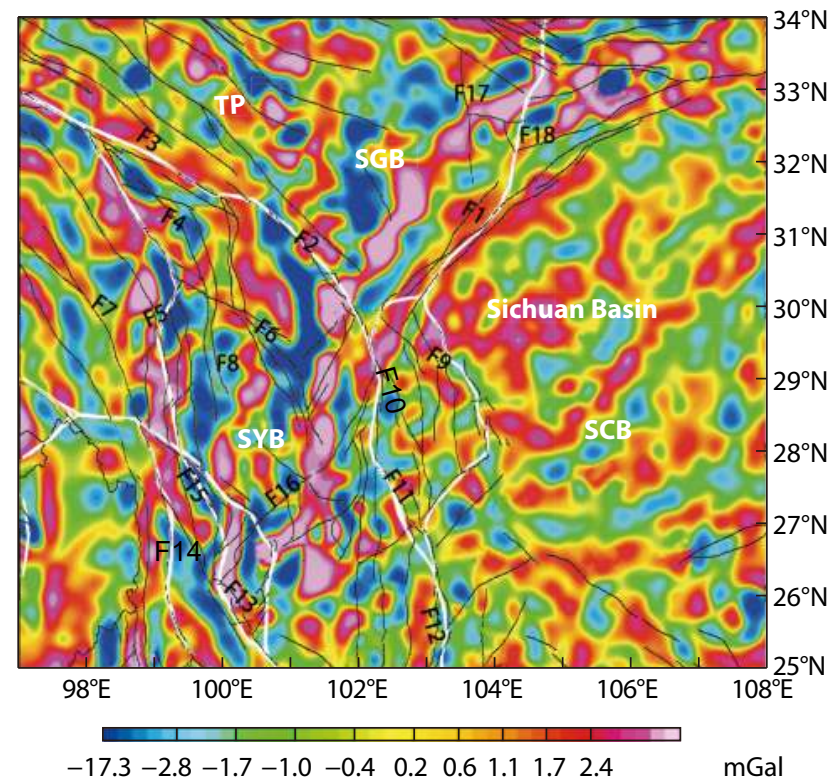

$$
\Delta g=A_{f} f(x, y)+\sum_{j=1}^{J} \sum_{\varepsilon=1}^{3} D_{j}^{\varepsilon} g(x, y)
$$

Using WT and MA principles, the gravity anomaly $\Delta g(x, y)$ can be decomposed into a smooth approximation of the low-frequency part $A_{J} f(x, y)$ and the sum of the wavelet details $\sum_{j=1}^{J} D_{j} g(x, y)$. $A_{f} f(x, y)$ is the J-order wavelet approximation of the gravity anomaly $(J \geq 2, J \in \mathrm{R})$. And $D_{j} g(x, y)$ is the each order detail by $J$ times WT decomposition $(j=1,2, \ldots, J)$. The order of the decomposition can be freely chosen; that is, the value of $J$ is artificially selected. According to the low-order wavelet detail invariance principle (Yang WC, 2001), the order is judged after the approximation is

(b)

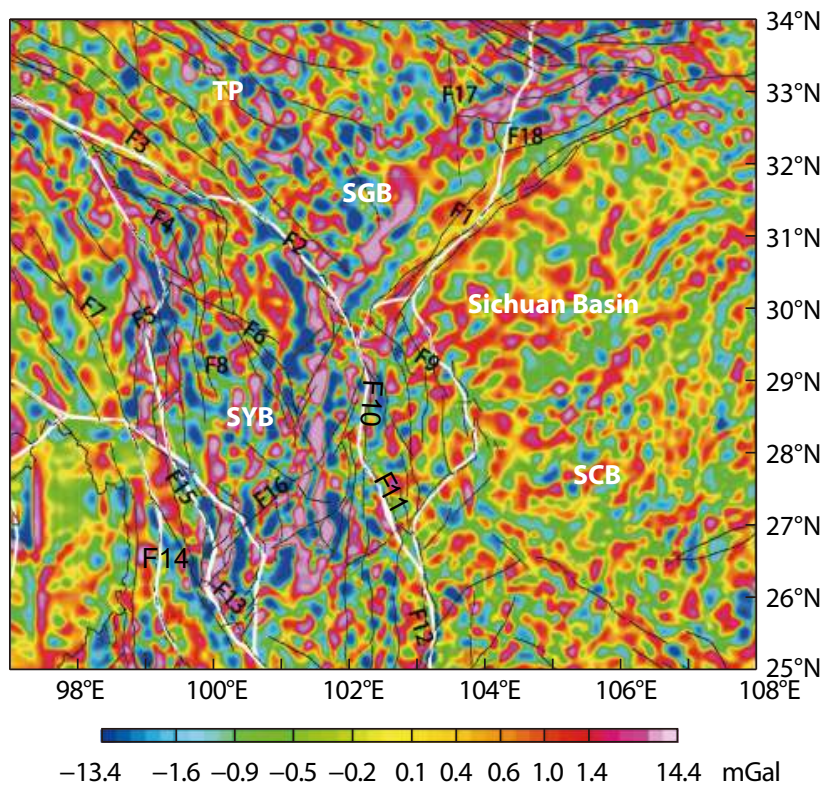

(d)

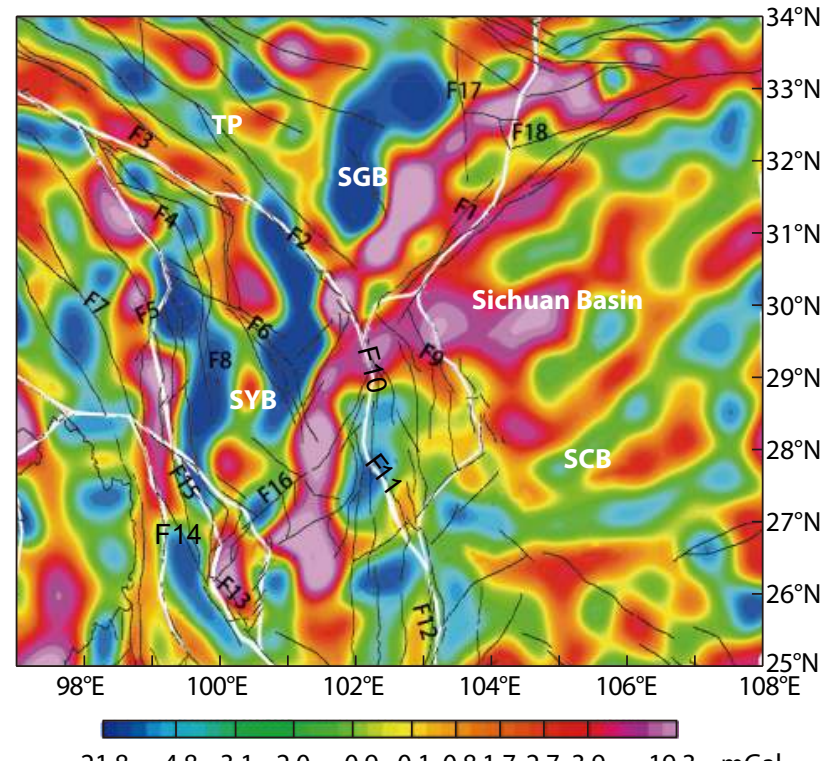

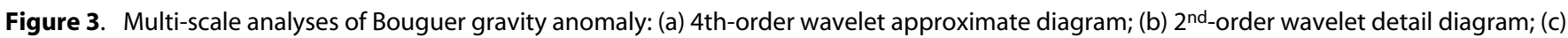
$3^{\text {rd }-o r d e r ~ w a v e l e t ~ d e t a i l ~ d i a g r a m ; ~(d) ~} 4^{\text {th }}$-order wavelet detail diagram. The abbreviations of tectonic blocks and faults are defined in the caption of Figure 1. 
obtained, and if the approximation has a smooth regional field feature, it can be selected as the final order. We chose $J=4$. Therefore, the expression of the gravitational decomposition can be summarized as

$$
\Delta g=A_{4} f(x, y)+\sum_{j=1}^{4} \sum_{\varepsilon=1}^{3} D_{j}^{\varepsilon} g(x, y)=A_{4} G+D_{1} G+D_{2} G+D_{3} G+D_{4} G
$$

in which $A_{4} G$ is the $4^{\text {th }}$-order wavelet approximation of the gravity field, and $D_{1} G$ to $D_{4} G$ are the BA wavelet details from the $1^{\text {st }}$ to the $4^{\text {th }}$ order.

\section{Results}

\subsection{Multiscale Analysis (MA) of the BA in the SE Margin of the Tibetan Plateau}

Based on WT and MA principles, we performed MA of the BA in the SE margin of the Tibetan Plateau. The WT approximation diagram is a reflection of the regional BA information, which primarily characterizes the large-scale low-frequency anomaly (Figure 3a). This information presents the Moho depth change and the density change in the lower crust and the uppermost mantle caused by the anomaly composition. The MA of the BA in the Chinese mainland shows that the 4th-order wavelet approximation of the gravity field primarily reflects the density of the Moho and the upper mantle rock (Yang WC, 2009). The 4th-order approximation diagram (Figure 3a) suggests a density difference between the lithospheric mantle and the Moho undulation and illustrates the obviously partitioned characteristics of the gravity anomalies. There is an obvious gravity gradient zone in the Yshaped fault joint zone. This zone is composed of three active tectonic belts, that is, the Longmenshan, Xianshuihe and Anninghe. In the study area, the value of the BA is low in the NW and increases gradually to the SE. Local high-BA traps still exist in the SCB to the east of the gradient zone, and the high BA areas indicate the existence of a high-density and relatively hard block beneath the basin, which prevents the material of the Tibetan Plateau from moving eastward and turning southward. The regional distribution of the BA field in Figure $3 a$ is consistent with the Moho depth variation obtained via seismic methods (Wang CY et al., 2010; Meng XH et al., 2012).

The WT detail is a reflection of the local field BA information, which primarily shows the small scales of the high-frequency anomaly information. Statistically, the WT approximation and the WT details reflect anomaly information at different depths. Using the power spectrum method, the approximate depth of the field source corresponding to each order of the WT approximation and the WT detail analysis diagram can be obtained. Due to the low resolution of the satellite gravity data to of the deep field source, the depth information given by the power spectrum method is only a statistical estimation and therefore provides only a reference depth (Bhimasankaram et al., 1977; Yang WC et al., 1979; Yang WC, 1986). The BA of the $1^{\text {st }}$-order detailed WT primarily reflects the distribution of the low-density material near the surface. Therefore, the deep crustal structure characteristics may be revealed by the 2 nd to 4 th order detail diagrams (Figures $3 b-3 d$ ).

The 2nd-order BA detail diagram (Figure 3b) reflects the trans- verse anisotropy of the upper crust density. According to the power spectrum, the buried depth of the detail wavelet gravity field source is approximately $15 \mathrm{~km}$. The BA is presented in the forms of traps with different scales, which primarily reflects the heterogeneity in the distribution of the sedimentary strata near the upper crust, the density of the shallow crust, and the divergence in density and texture of various complex block units. The diagram indicates that the principal direction of the anomaly trap in the SGB strikes NW and that the gravity gradient zone in this block is distributed along the fault. Mild variations in the $B A$ value in the SCB indicate a stable variation of the litho-density in the upper crust. The strike of the principal direction of the gravity gradient zone within the Sichuan-Yunnan rhombic block changes from NNW in the northern part to approximately NS in the southern part. This reflects the lateral slip of the SYB forced by the Tibetan Plateau (Zhang YQ et al., 2010). The boundary between the Sichuan Basin and the SGB is an obvious trapped gravity gradient zone in the NE direction, which coincides with the Longmenshan fault zone. On the western side of the Longmenshan fault zone, there is a poor continuity of the triped BA traps of alternating positive and negativeand the distribution of their gradients is along the Longmenshan fault zone. On the eastern side of the Longmenshan fault zone, there are primarily discontinuous beaded shaped negative gravity anomalies. Similarly, there are several NStrending striped positive gravity gradient zones on the left side of the Anninghe fault zone and there are the negative gravity gradient zones of comparable sizes on the right side. Figure $3 \mathrm{~b}$ shows that the partitioning characteristics of the BA are not obvious (Wang CY et al., 2010).

The field source depth of the 3rd-order detail diagram is approximately $30 \mathrm{~km}$, which reflects the inhomogeneity of the crust's litho-density at meso-scale (Figure 3c). According to the crustal thickness (Yang WC et. al., 2001), the divergent distribution of crust litho-density also appears in the middle crust between SYB and SGB, as well as in the lower crust of SCB, indicating that the range of the low BA in SYB and SGB is expanded. The principal direction of the anomaly trap is basically the same as that of the tectonic stress field. From north to south, the direction changes from SE to nearly NS. The high-density and low-density geological bodies, revealed by these positive and negative BA zones, are local compressive fault-uplift and strike-slip fault structures caused by the unbalanced forces in the eastern margin zone of the Tibetan Plateau, which resulted in lateral anisotropy of density in the middle crust (Zhang YQ et al., 2009). The SCB exhibits positive gravity anomalies; however, the high BA toward the NE on the western side of the block reflects the NE direction of the local folding of the lower crust due to the SE direction compression of the SGB (Cheng WZ et al., 2003). The positive high BA along the Longmenshan and the Anninghe fault zones is very obvious. In addition, the high BA traps of the two fault zones are connected, indicating that the Longmenshan and the Anninghe fault zones merge in the middle crust (Zhang JS et al., 2009). In the Xianshuihe fault zone, the value of the high-BA gradient zone is small. In the southern segment of the fault, there is a negative BA zone running approximately in the NS direction, near the boundary of the Sichuan-Yunnan rhombic block. This agrees with the observation of an ultra-high Poisson ratio in this area (Wang CY et al., 2010). 
In the 4th-order detail diagram (Figure 3d), the Bouguer gravity traps in the form of bands are further increased, and the positive/negative anomaly bands are listed in different phases. According to the power spectrum, the buried depth of the detail wavelet gravity field source is approximately $55 \mathrm{~km}$. Compared to the 3 rd-order details diagram, the morphological variation here is greater. The 4th-order detail diagram reflects primarily the density structure from the bottom lower crust to the top of the upper mantle. The anomaly zones are clear and continuous. The location of the wavelet detail is basically consistent with the surface fault. At the same time, there are some incomplete coincidences, which may be caused by the change of dip angle when the fault extends downward. It shows a continuous positive gravity gradient zone along the Longmenshan and the Anninghe fault zones where the principal direction of the linear anomaly area located in the northeast part strikes primarily in the NE and EW directions. The principal direction of the linear anomaly area in the southwest part strikes from NS in the south to NW in the north. The range of high gravity anomalies in the fault zone is further enlarged, and the maximum anomaly value also increases (Li $Y$ et al., 2005). These observation suggest the existence of geological bodies in higher density in the fault zone at the top of the lower crust, caused by the upwelling of high density materials in the upper mantle or asthenosphere (Long SS and Zhao Z, 2000). In the northeast of the gradient zone, there is still a widespread positive $\mathrm{BA}$ zone in the $\mathrm{SCB}$, with mild variations in the gravity value. Even though the gravity values in the southern SCB show a large range of negative gravity anomalies, the variation in the gravity values is very slow, which reflects the relatively consistent litho-density and stability structures in the SCB's upper mantle (Yang WC and Yu $C Q, 2014 a, b)$. There are positive and negative alternating gravity gradient zones in the SYB, which migrate distinctively from the SSE direction to approximately the NS direction. These gradient zones are controlled locally by the main faults in the block. This reflects the extensive folding of the SYB in the lower crust by the eastward thrust compression of the Tibetan Plateau. Due to the continuous uplift of the Tibetan Plateau, a partial crustal depression structure was produced by the clockwise rotation and strikeslip movement of the block. Therefore, in the SYB many faults are thrust faults and strike-slip faults.

As is shown in the detail diagrams of the $2^{\text {nd }}$, $3^{\text {rd }}$, and $4^{\text {th }}$-order wavelets of the BA field, the BA in the Sichuan Basin is relatively high, and the distribution of the BAs of a series of approximately parallel belts in the Sichuan Basin is similar to that in the Longmenshan fault zone. The characteristics of the BAs in other regions show many differences. The BA value in the Sichuan Basin is lower than that in the SGB, and that in the SYB varies rapidly, where the internal BA shows high heterogeneity. It is clear that the Sichuan-Yunnan rhomboid block, as a strongly active tectonic unit, is possibly composed of sub-blocks of different properties.

\subsection{Large Earthquake in SE Margin Zone of Tibetan Plateau}

The tectonic setting in the SE margin zone of the Tibetan Plateau is complicated. The Plateau's east margin zone is in the process of continuous uplift and crustal thickening due to the Plateau's east-

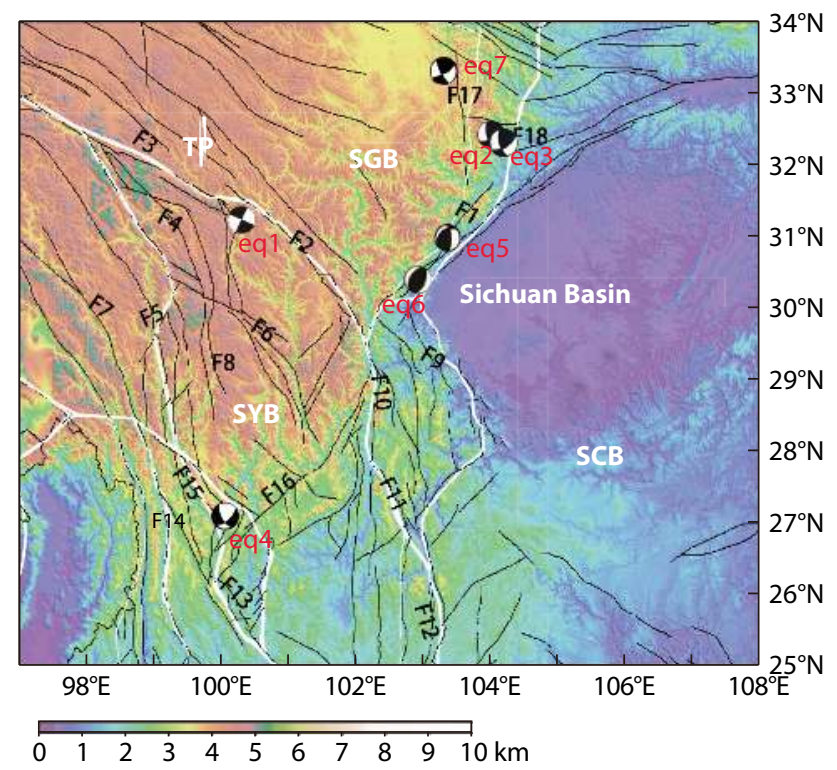

Figure 4. Distribution of focal mechanisms of large earthquakes since 1970 to 2018 Beach balls are focal mechanisms, which are obtained from the earthquake catalogue of the National Earthquake Information Center, USA. The black line represents the fault. The white line represents the boundary of the block. The abbreviations of tectonic blocks and faults are defined in the caption of Figure 1.

ward compression and the obstruction of the SCB. The deep crust of the western Sichuan region is in an uneven state (Wang $Q$ et al., 2008). This complicates the tectonic activities and causes intense earthquake activity. The occurrence of earthquakes in the SE margin zone of the Tibetan Plateau is primarily controlled by active faults. The BA zones are correlated with the distribution of earthquakes. The anomalies on both sides of the fault reflect obvious differences in the physical properties and structures on the two sides (Wang CY et al., 2010; Zhang ZQ and Gao Y, 2019). These differences are often conducive to the accumulation of stress and relative energy, as well as the occurrence of earthquakes. Earthquakes are the result of a sudden failure of the fault plane caused by the accumulation of strain energy on the fracture surface under the action of regional tectonic stress and some triggering or reaching of the fracture endurance limit (Scholz, 1998). Seven earthquakes with magnitudes greater than or equal to $M_{\mathrm{S}} 7.0$ are recorded since 1970 in the study area's earthquake catalogue, two of which were in the Longmenshan fault zone, three around the Minjiang and Huya faults, and one each in the Xianshuihe, and Lijiang-Xiaojin fault zones (Figure 4, Table 1). The Minjiang and the Huya faults are NW extensions of the Longmenshan fault zone. All the large earthquakes occurred in block boundary zones or near to a boundary (Deng, QD et al., 2014).

The 4th-order approximation diagram (Figure 5a) shows the distribution of the seven large earthquakes from 1970 to 2018, reflecting characteristics of the large earthquakes in the regional field of the BA in the study area. In Figure 5a, the most obvious gravity gradient zone is around the Longmenshan fault zone. The two $M_{S}$ 7.2 earthquakes in Songpan-Pingwu (1976), the $M_{S} 8.0$ earthquake in Wenchuan (May 12, 2008), and the $M_{S} 7.0$ earthquake in Lushan (April 20, 2013) occurred in this gravity gradient zone. Ac- 
Table 1. Earthquake catalog of magnitudes $M_{\mathrm{S}} 7.0$ and larger since 1970

\begin{tabular}{lcccccc}
\hline No. & Earthquake name & Magnitude $\left(M_{\mathrm{S}}\right)$ & Date $(\mathrm{yyyy}-\mathrm{mm}-\mathrm{dd})$ & Lat. $\left({ }^{\circ} \mathrm{N}\right)$ & Long. $\left({ }^{\circ} \mathrm{E}\right)$ & Focal depth $(\mathrm{km})$ \\
\hline eq1 & Luhuo & 7.6 & $1973-02-06$ & 31.500 & 100.400 & 17 \\
eq2 & Songpan-Pingwu & 7.2 & $1976-08-16$ & 32.700 & 104.080 & 15 \\
eq3 & Songpan-Pingwu & 7.2 & $1976-08-23$ & 32.480 & 104.150 & 22 \\
eq4 & Lijing & 7.0 & $1996-02-03$ & 27.300 & 100.220 & 10 \\
eq5 & Wenchuan & 8.0 & $2008-05-12$ & 31.000 & 103.400 & 14 \\
eq6 & Lushan (Ya'an) & 7.0 & $2013-04-20$ & 30.300 & 102.990 & 17 \\
eq7 & Jiuzhaigou & 7.0 & $2017-08-08$ & 33.200 & 103.820 & 20 \\
\hline
\end{tabular}

(a)

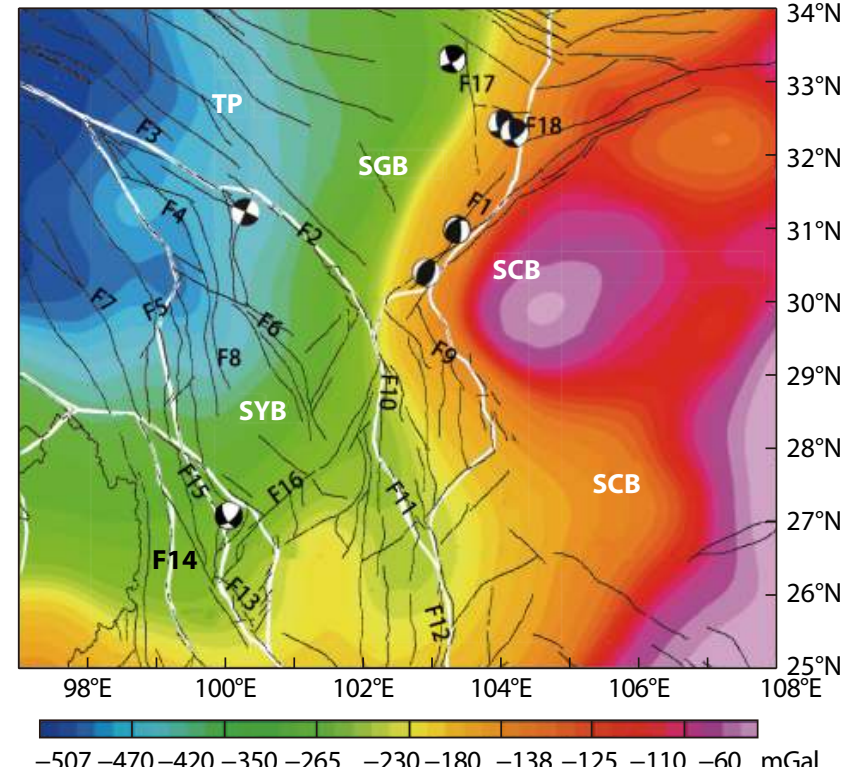

(c)

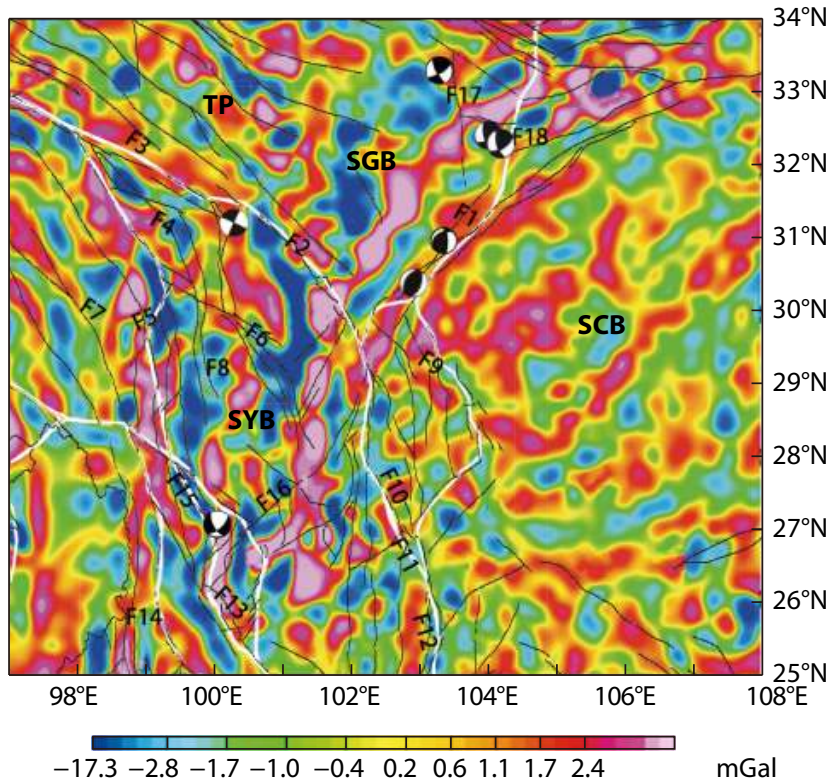

(b)

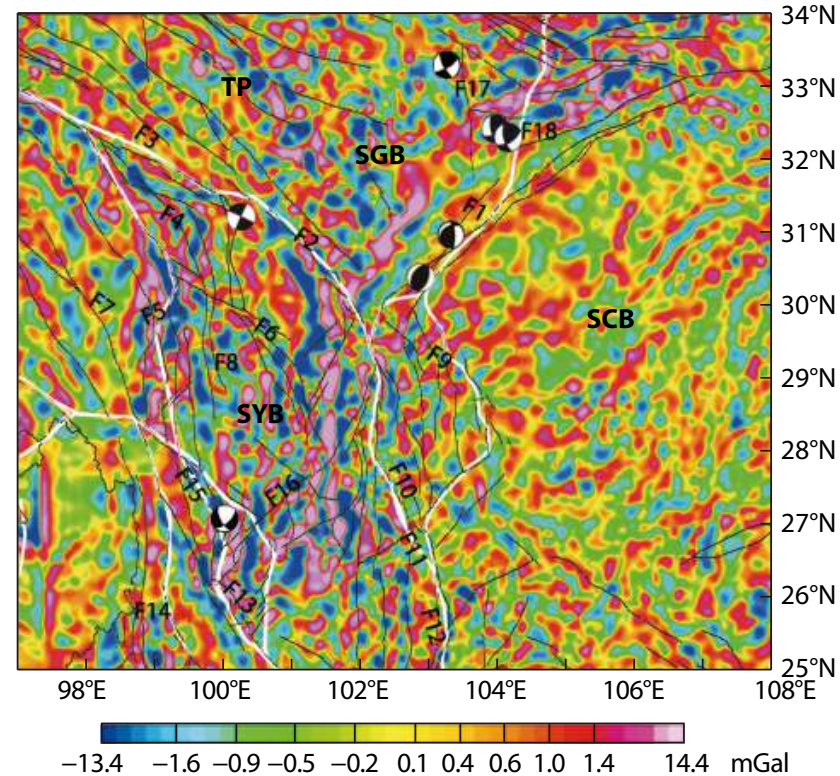

(d)

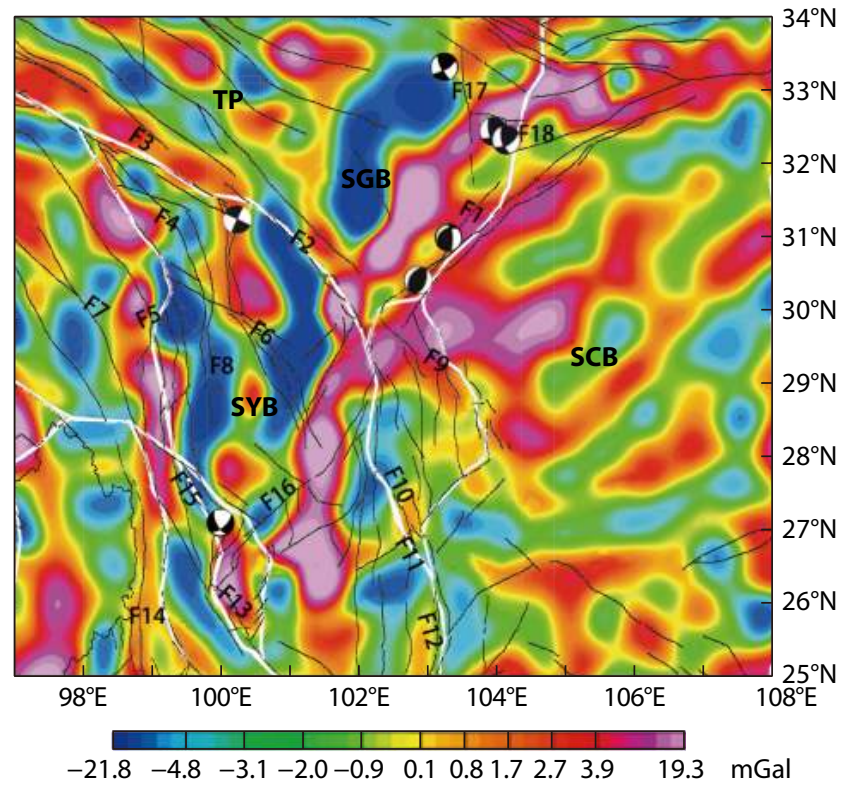

Figure 5. A comparison of the focal mechanisms of $M_{S} 7 \cdot 0^{+}$earthquakes and the Bouguer gravity anomaly of multi-scale wavelet: (a) distribution of focal mechanisms in 4th-order wavelet approximate diagram; (b) distribution of focal mechanisms in 2nd-order wavelet detail diagram; (c) distribution of focal mechanisms in 3rd-order wavelet detail diagram; (d) distribution of focal mechanisms in 4th-order wavelet detail diagram. The abbreviations of tectonic blocks and faults are defined in the caption of Figure 1. 
cording to the MA of the BA, the Longmenshan gravity gradient zone shows a dominant direction consistent with the Longmenshan fault zone, and the gravity field characteristics on both sides of the gradient zone are obviously different. This indicates great changes in the crustal material and structure in the Longmenshan fault zone.

In the 2nd-order wavelet detail diagram (Figure 5b), the two sides of the Longmenshan fault zone are characterized by long and narrow line-shaped Bouguer gravity traps. In the 3rd-order detail diagram (Figure $5 \mathrm{c}$ ), the fault zone manifests in the shape of a relatively continuous gravitational gradient zone. The gravity anomalies on both sides of the fault zone are clearly divided, showing the existence of high-density material upwelling (Wang $E$ et al., 1998). The Longmenshan block is characterized by a large-scale low positive BA trap in the 4th order wavelet detail diagram (Figure $5 \mathrm{~d}$ ), which reflects a wide range of low-density geological structures in the lower crust. This is consistent with the seismic velocity structure (Lei JS et al., 2009). There are obvious low wave velocity anomalies in the lower crust beneath the Longmenshan fault zone; these reveal an overpressure fractured rock mass in the lower crust, which results in a low-density anomaly in the lower crust, forming a negative low-BA trap. The Wenchuan and Lushan earthquakes occurred in the high-speed zone (Figure 5b). Both were thrust-type earthquakes and occurred in the southern part of the Longmenshan nappe tectonic belt. The compression of the Indian Plate into the Tibetan Plateau that caused the channel flow eastward was subsequently obstructed by rigid blocks in the lower crust and upper mantle of the Sichuan Basin. This resulted in the shortening and uplifting of the crust in the Longmenshan fault zone. According to the 2nd-4th details (Figures 5b-5d), some material has been accumulated in the middle and lower crust of the Longmenshan fault zone, resulting in stress concentration and upwelling. Therefore, the bottom of the upper crust is in a state of high stress growth (Lu RQ et al., 2017). We may infer that the long-term accumulation of tectonic stress along the Longmenshan fault zone and its final release resulted in the occurrence of the Wenchuan and Lushan earthquakes. The direction of the principal compressive stress in the source zone is NW, nearly perpendicular to the fault strike. Two stress-enhanced zones have emerged in the area beyond the middle and northern parts of the Longmenshan fault (McCann et al., 1979).

As a result, the southeast apex and the northeast apex of the SGB extrude toward the $\mathrm{SE}$ and $\mathrm{NE}$, respectively, forming an arcshaped tectonic system. During the NE-trending extrusion process in the NE apex of the SGB, the Huya fault was blocked by the Qinling Mountains, which resulted in the upstream and left-lateral strike-slip of the Huya fault. According to Coulomb stress transfer theory, the Jiuzhaigou $M_{\mathrm{S}} 7.0$ earthquake on August 8, 2017 may be the result of stress transfer and triggering after the 2008 $M_{S}$ 8.0 Wenchuan earthquake (Xu XW et al., 2017). According to our MA of the BA, the Huya fault is characterized by thrust and left-lateral strike-slip. The focal mechanism solutions of the Jiuzhaigou earthquake and the two $M_{\mathrm{s}} 7.2$ Songpan-Pingwu earthquakes in 1976 exhibit thrust with left-lateral strike-slip. It is likely that the focal mechanisms of these earthquakes are closely related to the faults.
The Luhuo $M_{S} 7.6$ earthquake (February 6, 1973) occurred in the western branch of the Xianshuihe fault zone on the Garzê-Yushu fault, with left-lateral strike-slip. As is shown in the BA diagram (Figure 2), the Xianshuihe fault zone and its branches are located in the stable area of the BA. The Quaternary and present tectonic deformations in this area are controlled by NWW and nearly NS structures (Li ZD and Gao ZJ, 2016). The NW trending structure is characterized by left-lateral shear; it gradually transits eastward to a nearly NS-trending structure. An arc-shaped structural belt protrudes toward the NE. The distorted anomaly axis is shown on the 3rd and 4th order detail diagrams of the Yushu fault zone, which, together with the Xianshuihe fault zone, are in the vicinity of Garzê, constituting the southern boundary of the SGB. This is consistent with the pull-apart zone of the left order oblique formation between the Garzê-Yushu fault zone and the Xianshuihe fault zone. There is a negative low-BA zone in the southern segment of the Xianshuihe fault zone, which is found near the boundary of the SYB with clockwise rotation. The formation of local strike-slip faulted structures resulted in litho-fragmentation and the formation of multi-void fractures at the block boundary. The density of strike-slip faulted structures is lower than that of the surrounding geological body, which is consistent with the conclusion of a locally ultra-high Poisson' ratio (Wang CY et al., 2010). This indicates a relatively wide fold in the lower crust of the SYB, in the tectonic background of the east-trending thrust pressure and the whole uplift of the Tibetan Plateau. Due to the clockwise rotation and strike-slip movement of the block, local crustal faulted structures were formed, resulting in the varying high and low densities of geological bodies arranged in the EW direction and distributed in nearly the NS direction. Relative differential movement between tectonic blocks is the cause of the Luhuo earthquake, which was predominately strike-slip (Li ZD and Gao ZJ, 2016). In Figure 5 , the Luhuo earthquake is seen to have occurred in a high-BA zone, in whose southeast lower crust there is largescale low-BA trap. We suspect that this large-scale low-BA trap was originally located below and surrounded by a high BA zone. Due to the clockwise rotation and strike-slip motion of the block, a rupture occurred in the high-BA zone of the upper crust, while the low-BA trap of the lower crust slipped southeast.

The Lijiang earthquake (February 3, 1996) occurred in the SYB, which is a small triangular block surrounded by three groups of faults. It can be seen from the 2nd-order wavelet detail diagram that there exists a high-BA trap with NE principal direction. There is lateral heterogeneity in the crust high-speed block ( $\mathrm{Su} Y \mathrm{YJ}$ and Liu ZY, 1997). The high-BA traps of 3rd and 4th detail expand clearly, which indicates a high-density material upwelling phenomenon. This is consistent with the pull-apart zone of the left order oblique formation between the Garzê-Yushu and the Xianshuihe fault zones. There is a negative low-BA zone in the south segment of the Xianshuihe fault zone, which is located near the boundary of the SYB with clockwise rotation. The formation of local strike-slip faulted structures resulted in lithospheric fragmentation and formation of a multi-void high-density material upwelling phenomenon. In particular, the 3rd order anomaly is at the center of the high anomaly trap, surrounded by low anomalies (Figure $5 \mathrm{~b}$ ), which is the same as the pattern of previous earthquakes. This indicates that strong vertical stresses were 
caused by the uplift of mantle material, in addition to horizontal stresses (Su YJ and Liu ZY, 1997).

\section{Discussion and Conclusions}

Different order anomaly diagrams show that the normal high-BA range in the Longmenshan and Anninghe fault zones has been further expanded, that the maximum of the anomaly values has also increased, and that there is an upward phenomenon of highdensity magmatic material. There are many dense geologic bodies along the faults at the top of the lower crust, which are inferred to have been caused by the upwelling of high-density materials in the upper mantle and asthenosphere. The different order gravity values in the SCB change gradually, which indicates a relatively simple density structure. The south-central segment of the Xianshuihe fault zone is located along the boundary of the SYB, which reflects the lateral slip movement of the SYB under the overall force of the Tibetan Plateau. Therefore, the Xianshuihe and the Anninghe-Zemuhe faults zones are caused by staggered slip and these faults are all strike-slip faults. Compared to the Garzê-Yushu fault, the BA along the Anninghe-Zemuhe fault zone is lower than that of the two sides, showing that the crustal density under the faults is relatively smaller than that on the two sides of the faults. Such a density distribution helps the SYB extrude in the lateral direction of the faults. Analyzing the characteristics of the BA at different orders indicates that the eastern Himalayan syntaxis has produced a strong eastward push during its northward movement, resulting in a shortening of the crust from west to east. However, due to the rapid uplift of the Tibetan Plateau under the influence of gravity, the crustal material is creeping eastward, resulting in lower crustal flow and a corresponding horizontal push force. Under the combined action of these two factors, the SGB and SYB are driven to slip and extrude southward and eastward laterally. By comparing and analyzing the characteristics of the BA at different orders and comparing these data to the greater than or equal to $M_{S} 7.0$ earthquakes from 1970 to 2018, we could infer that the Wenchuan and the Lushan earthquakes occurred on the eastern boundary of the Songpan-Garzê Block in the Longmenshan thrust nappe belt. In addition, the Songpan-Pingwu and Jiuzhaigou earthquakes occurred in the Huya and Minjiang faults, respectively, along the western boundary of the Songpan-Garzê Block, which is the Garzê-Yushu fault zone. The Lijiang earthquake occurred on the Lijing-Xiaojin fault zone in the SYB. These earthquakes occurred primarily in high density areas of the upper crust, indicating that large earthquakes occur usually in active blocks and in the boundary zones of blocks, and that active faults are closely related to large earthquakes. It is further inferred that large earthquakes occur primarily in active fault zones with a high density upper crust and large and wide low-BA traps in the lower crust and uppermost mantle.

\section{Acknowledgments}

This study was supported by the National Natural Science Foundation of China (Project 41730212) and the Basic Research Project of the Institute of Earthquake Forecasting, China Earthquake Administration (Grant No. 2017IES0102).

\section{References}

Bhimasankaram, V. L. S., Nagendra, R., and Rao, S. V. S. (1977). Interpretation of gravity anomalies due to finite inclined dikes using Fourier transformation. Geophysics, 42(1), 51-59. https://doi.org/10.1190/1.1440713

Burchfiel, B. C., Royden, L. H., van der Hilst, R. D., Hager, B. H., Chen, Z., King, R.W., Li, C., Lü, J., Yao, H., and Kirby, E. (2008). A geological and geophysical context for the Wenchuan earthquake of 12 May 2008, Sichuan, People's Republic of China. GSA Today, 18(7), 4-11. https://doi.org/10.1130/GSATGI8A.1

Chen, S., Xu, W. M., Shi, L., Lu, H. Y., and Guo, F. Y. (2013). Gravity field and lithospheric mechanical properties of Longmenshan fault zone and its surrounding areas. Acta Seismol. Sin. (in Chinese), 35(5), 692-703. https://doi.org/10.3969/j.issn.0253-3782.2013.05.008

Cheng, W. Z., Diao, G. L., Lü, G. P., Zhang, Y. J., Li, G. F., and Chen, T. C. (2003). Focal mechanisms, displacement rate and mode of motion of the SichuanYunnan block. Seismol. Geol., 25(1), 71-87.

Clark, M. K., and Royden, L. H. (2000). Topographic ooze: building the eastern margin of Tibet by lower crustal flow. Geology, 28(8), 703-706. https://doi.org/10.1130/0091-7613(2000)28<703:TOBTEM>2.0.CO;2

Deng, Q. D., Cheng, S. P., Ma, J., and Du, P. (2014). Seismic activities and earthquake potential in the Tibetan Plateau. Chinese J. Geophys. (in Chinese), 57(7), 2025-2042.

England, P., and Houseman, G. (1986). Finite strain calculations of continental deformation: 2. Comparison with the India-Asia collision zone. J. Geophys. Res., 91(B3), 3664-3676. https://doi.org/10.1029/JB091iB03p03664

Fu, G. Y., Zhu, Y. Q., Gao, S. H., Liang, W. F., Jin, H. L., Yang, G. L., Guo, S. S., and $\mathrm{Xu}, \mathrm{Y} . \mathrm{M}$. (2013). Discrepancies between free air gravity anomalies from EGM2008 and the ones from dense gravity/GPS observations at west Sichuan Basin. Chinese J. Geophys. (in Chinese), 56(11), 3761-3769. https://doi.org/10.6038/cjg20131117

Fullea, J., Fernández, M., and Zeyen, H. (2008). FA2BOUG-A FORTRAN 90 code to compute Bouguer gravity anomalies from gridded free-air anomalies: application to the Atlantic-Mediterranean transition zone. Comput. Geosci., 34(12), 1665-1681. https://doi.org/10.1016/j.cageo.2008.02.018

Hou, Z. Z., and Yang, W. C. (1997). Wavelet transform and multi-scale analysis on gravity anomalies of China. Chinese J. Geophys. (in Chinese), 40(1), 85-95.

Hou, Z. Z., and Yang, W. C. (2011). Multi-scale inversion of density structure from gravity anomalies in Tarim Basin. Sci. China Earth Sci., 54(3), 399-409. https://doi.org/10.1007/s11430-011-4169-2

Jiang, F. Z., and Fang, J. (2001). Gravity field separation, density inversion and crustal tectonics in Kang-Dian region. Acta Seismol. Sin. (in Chinese), 23(4), 391-397. https://doi.org/10.3321/j.issn:0253-3782.2001.04.006

Jiang, X. D., and Jin, Y. (2005). Mapping the deep lithospheric structure beneath the eastern margin of the Tibetan Plateau from gravity anomalies. J. Geophys. Res., 110(B7), 3676. https://doi.org/10.1029/2004JB003394

Jin, H. L., Gao, Y., Su, X. N., and Fu, G. Y. (2019). Contemporary crustal tectonic movement in the southern Sichuan-Yunnan block based on dense GPS observation data. Earth Planet. Phys., 3(1), 53-61. https://doi.org/10.26464/epp2019006

Lei, J. S., Zhao, D. P., Su, J. R., Zhang, G. W., and Li, F. (2009). Fine seismic structure under the Longmenshan fault zone and the mechanism of the large Wenchuan earthquake. Chinese J. Geophys. (in Chinese), 52(2), 339-345.

Li, Y., Xu, G. D., Zhou, R. J., Densmore, A. L., and Ellis, M. A. (2005). Isostatic gravity anomalies in the Longmen Mountains and their constraints on the crustal uplift below the mountains on the eastern margin of the QinghaiTibet Plateau. Geol. Bull. China (in Chinese), 24(12), 1162-1168. https://doi.org/10.3969/j.issn.1671-2552.2005.12.012

Li, Z. D., and Gao, Z. J. (2016). Characteristics and distribution of earthquake relics at Luhuo and their scientific value. Acta Geol. Sichuan (in Chinese), 36(2), 213-216.

Long, S. S., and Zhao, Z. (2000). Characteristics of the seismic source stress field in the joint region of Xianshuihe, Longmenshan and An'ninghe faults. Acta Seismol. Sin., 13(5), 491-498. https://doi.org/10.1007/s11589-000-0048-1

Lou, H., and Wang, C. Y. (2005). Wavelet analysis and interpretation of gravity data in Sichuan-Yunnan region, China. Acta Seismol. Sin., 18(5), 552-561. https://doi.org/10.1007/s11589-005-0034-8

Lu, R. Q., Xu, X. W., He, D. F., John, S., Liu, B., Wang, F. Y., Tan, X. B., and Li, Y. Q. 
(2017). Seismotectonics of the 2013 Lushan $M_{w} 6.7$ earthquake: inversion tectonics in the eastern margin of the Tibetan plateau. Geophys. Res. Lett., 44(16), 8236-8243. https://doi.org/10.1002/2017GL074296

Ma, Z. W., Lu, Y., and Fang, J. (2017). Direct calculation method for multi-scale analysis of the gravity field with radial basis functions. Prog. Geophys. (in Chinese), 32(4), 1474-1482. https://doi.org/10.6038/pg20170408

Mallat, S. G. (1989). Multifrequency channel decompositions of images and wavelet models. IEEE Trans. Acoust., Speech, Sign. Process., 37(12), 2091-2110. https://doi.org/10.1109/29.45554

Mallat, S. H., and Hwang, W. L. (1992). Singularity detection and processing with wavelets. IEEE Trans. Inform. Theory, 38(2), 617-643. https://doi.org/10.1109/18.119727

McCann, W. R., Nishenko, S. P., Sykes, L. R., and Krause, J. (1979). Seismic gaps and plate tectonics: Seismic potential for major boundaries. Pure Appl. Geophys., 117(6), 1082-1147. https://doi.org/10.1007/BF00876211

Meng, X. H., Shi, L., Guo, L. H., Tong, T., and Zhang, S. (2012). Multi-scale analyses of transverse structures based on gravity anomalies in the northeastern margin of the Tibetan Plateau. Chinese J. Geophys. (in Chinese), 55(12), 3933-3941. https://doi.org/10.6038/j.issn.0001-5733.2012.12.006

Molnar, P., and Tapponnier, P. (1975). Cenozoic tectonics of Asia: effects of a continental collision: Features of recent continental tectonics in Asia can be interpreted as results of the India-Eurasia collision. Science, 189(4201), 419-426. https://doi.org/10.1126/science.189.4201.419

Ren, F. L., Xiao, Y., Zhu, X. Y., Li, S. Q., Guo, F. X., and Wu, L. G. (2018). Research on the relationship between multi-scale satellite gravity decomposition and field source depth. J. Geod. Geodyn. (in Chinese), 38(5), 533-538. https://doi.org/10.14075/j.jgg.2018.05.019

Royden, L. H., Burchfiel, B. C., King, R. W., Wang, E., Chen, Z. L., Shen, F., and Liu, Y.P. (1997). Surface deformation and lower crustal flow in eastern Tibet. Science, 276(5313), 788-790. https://doi.org/10.1126/science.276.5313.788

Scholz, C. H. (1998). Earthquakes and friction laws. Nature, 391(6662), 37-42. https://doi.org/10.1038/34097

Smith, W. H. F., and Sandwell, D. T. (1994). Bathymetric prediction from dense satellite altimetry and sparse shipboard bathymetry. J. Geophys. Res., 99(B11), 21803-21824. https://doi.org/10.1029/94JB00988

Su, Y. J., and Liu, Z. Y. (1997). Discussion on the source environment and rupture process of the M7.0 Lijiang earthquake. J. Seismol. Res. (in Chinese), 20(1), 66-71.

Tapponnier, P., Peltzer, G., Le Dain, A. Y., Armijo, R., and Cobbold, P. (1982). Propagating extrusion tectonics in Asia: new insights from simple experiments with plasticine. Geology, 10(12), 611-616. https://doi.org/10.1130/0091-7613(1982)10<611:PETIAN>2.0.CO;2

Teng, J. W., Xiong, S. B., and Zhang, Z. J. (1997). Review and prospects for geophysical study of the deep lithosphere structure and tectonics in Qinghai-Xizang (Tibet) plateau. Chinese J. Geophys. (in Chinese), 40(S1), 121-139.

Thatcher, W. (2007). Microplate model for the present-day deformation of Tibet. J. Geophys. Res., 112(B1), B01401. https://doi.org/10.1029/2005JB004244

Wang, C. Y., Zhu, L. P., Lou, H., Huang, B. S., Yao, Z. X., and Luo, X. H. (2010). Crustal thicknesses and Poisson's ratios in the eastern Tibetan Plateau and their tectonic implications. J. Geophys. Res., 115(B11), B11301. https://doi.org/10.1029/2010JB007527

Wang, E., Burchfiel, B. C., Royden, L. H., Chen, L. Z., Chen, J. S., Li W. X., and Chen, Z. (1998). Late Cenozoic Xianshuihe-Xiaojiang, Red river, and Dali fault systems of southwestern Sichuan and central Yunnan, China (pp. 1-108). Geological Society of America Special. https://doi.org/10.1130/0-8137-2327-2.1

Wang, Q., Zhang, P. Z., Freymueller, J. T., Bilham, R., Larson, K. M., Lai, X. A., You, X. Z., Niu, Z. J., Wu, J. C.,... Chen, Q. Z. (2001). Present-day crustal deformation in China constrained by global positioning system measurements. Science, 294(5542), 574-577. https://doi.org/10.1126/science.1063647

Wang, Q. S., Teng, J. W., Zhang, Y. Q., and Yang, H. (2008). The effect of crustal gravity isostasy and Wenchuan earthquake in Longmenshan faults and adjacent area. Prog. Geophys. (in Chinese), 23(6), 1664-1670.

Wang, Q. S., Teng, J. W., Zhang, Y. Q., Zhang, X. M., and Yang, H. (2009). The crustal structure and gravity isostasy in the middle western Sichuan area. Chinese J. Geophys. (in Chinese), 52(2), 579-583.

Xiong, X., Wang, J. Y., and Teng, J. W. (2005). Deep mechanical background for the Cenozoic volcanism in the Tibetan Plateau. Earth Science- J. China Univ. Geosci., 16(4), 334-339.

Xu, X. W., Zhang, P. Z., Wen, X. Z., Qin Z. L., Chen G. H., and Zhu, A. L. (2005) Features of active tectonics and recurrence behaviors of strong earthquakes in the western Sichuan province and its adjacent regions. Seismol. Geol. (in Chinese), 27(3), 446-461. https://doi.org/10.3969/j.issn.02534967.2005.03.010

Xu, X. W., Chen, G. H., Wang, Q. X., Chen, L. C., Ren, Z. K., Xu, C., Wei, Z. Y., Lu, R. Q., Tan, X. B.,... Shi, F. (2017). Discussion on seismogenic structure of Jiuzhaigou earthquake and its implication for current strain state in the southeastern Qinghai-Tibet Plateau. Chinese J. Geophys. (in Chinese), 60(10), 4018-4026. https://doi.org/10.6038/cjg20171028

Yang, J. Y., Zhang, X. H., Zhang, F. F., Han, B., and Tian, Z. X. (2012). On the accuracy of EGM2008 earth gravitational model in Chinese Mainland. Prog. Geophys. (in Chinese), 27(4), 1298-1306. https://doi.org/10.6038/j.issn.10042903.2012.04.003

Yang, W. C., Guo, A. Y., Xie, Y. Q., et al. (1979). Interpretation of gravity anomalies in frequency domain (A). Comput. Tech. Geophys. Geochem. Expl. (in Chinese)(1), 1-16.

Yang, W. C. (1986). A generalized inversion technique for potential field data processing. Chinese J. Geophys. (in Chinese), 29(3), 283-291.

Yang, W. C., Shi, Z. Q., Hou, Z. Z., and Cheng, Z. Y. (2001). Discrete wavelet transform for multiple decomposition of gravity anomalies. Chinese J. Geophys. (in Chinese), 44(4), 534-541. https://doi.org/10.3321/j.issn:00015733.2001.04.012

Yang, W. C. (2009). Tectonophysics in Paleo-Tethys Domain (in Chinese). Beijing: Petroleum Industry Press.

Yang, W. C., and Yu, C. Q. (2014a). Continental collision process reveled by worldwide comparison of crust and upper mantle structures ( I ). Geol. Rev. (in Chinese), 60(2), 237-259. https://doi.org/10.16509/j.georeview.2014.02.002

Yang, W. C., and Yu, C. Q. (2014b). Continental collision process reveled by worldwide comparison of crust and upper mantle structures ( II ). Geol. Rev. (in Chinese), 60(3), 486-502. https://doi.org/10.16509/j.georeview.2014.03.002

Zandt, G., and Ammon, C. J. (1995). Continental crust composition constrained by measurements of crustal Poisson's ratio. Nature, 374(6518), 152-154. https://doi.org/10.1038/374152a0

Zhang, C. Y., Guo, C. X., Chen, J. Y., Zhang, L. M., and Wang, B. (2009). EGM 2008 and its application analysis in Chinese mainland. Acta Geodaet. Cartograph. Sin. (in Chinese), 38(4), 283-289. https://doi.org/10.3321/j.issn:10011595.2009.04.001

Zhang, J. S., Gao, R., Zeng, L. S., Li, Q. S., Guan, Y., He, R. Z., Wang, H. Y., and Lu, Z. W. (2009). Relationship between characteristics of gravity and magnetic anomalies and the earthquakes in Longmenshan range and adjacent areas. Chinese J. Geophys. (in Chinese), 52(2), 572-578.

Zhang, P. Z., Deng, Q. D., Zhang, G. M., Ma, J., Gan, W. J., Min, W., Mao, F. Y., and Wang, Q. (2003). Active tectonic blocks and strong earthquakes in the continent of China. China Sci. Ser. D: Earth Sci., 46(S2), 13-24. https://doi.org/10.1360/03dz0002

Zhang, Y. Q., Dong, S. W., and Yang, N. (2009). Active faulting pattern, presentday tectonic stress field and block kinematics in the east Tibetan plateau. Acta Geol. Sin., 83(4), 694-712. https://doi.org/10.1111/j.17556724.2009.00093.x

Zhang, Y. Q., Wang, Q. S., and Teng, J. W. (2010). The crustal isostatic anomaly beneath eastern Tibet and western Sichuan and its relationship with the distribution of earthquakes. Chinese J. Geophys. (in Chinese), 53(11), 2631-2638. https://doi.org/10.3969/j.issn.0001-5733.2010.11.011

Zhang, Z. J., Teng, J. W., Li, Y. K., Klemperer, S., and Yang, L. Q. (2004). Crustal structure of seismic velocity in southern Tibet and east-westward escape of the crustal material. Sci. China Ser. D: Earth Sci., 47(6), 500-506. https://doi.org/10.1360/03yd0518

Zhang, Z. Q., and Gao, Y. (2019). Crustal thicknesses and Poisson's ratios beneath the Chuxiong-Simao basin in the southeast margin of the Tibetan plateau. Earth Planet. Phys., 3(1), 69-84. https://doi.org/10.26464/epp2019008 